\title{
Monitoring Impact of Social Dominance Orientation in Bangladeshi Manufacturing Industries
}

\author{
Enamul Islam \\ Limkokwing University of Creative Technology, Malaysia \\ E-mail: enamul5085@gmail.com
}

Received: January 21, 2020 Accepted: February 20, 2020 Published: February 22, 2020

doi:10.5296/ber.v10i1.16254 URL: https://doi.org/10.5296/ber.v10i1.16254

\begin{abstract}
We see signs of conflict, chaos, confusion, extortion, blockage and street violence in Bangladesh as a regular phenomenon. Often workers are found in the street creating unwanted activities to draw the attention of the Government. The problems of intergroup discrimination are responsible for social inequality. The worker group tries to dominate over the managerial group in most enterprises. In any organisation, psychopathic individual works alone but while expressing criminal activities or destructive activities, they function as a cooperative group. Regardless of the form of creation, or the contents of its fundamental belief system, workers group tend to organise as group-based social hierarchies in which they often dominate another group (managerial group) and enjoy higher social status and power.

While scholars of developed nations have a greater interest in Social Dominance Orientation (SDO) study, little is known about least developed and developing nations. This quantitative cross-sectional study joins a serious of Social dominance orientation studies intending to explore the structure of the social dominance orientation scale in Bangladeshi manufacturing industries and if workers group has higher labels of social dominance orientation than managerial groups. The researcher found a significant difference between males and females on social dominance orientation at the workplace. Male showed a higher level of social dominance orientation than their female counterparts. Result also shows that members of disadvantaged groups (workers group) have high-level social dominance orientation. Workers group maintain oppression mainly by force and threat not by enjoying social supremacy but by strength and political orientation.
\end{abstract}

Keywords: Social dominance orientation, Social dominance theory, Hierarchy- attenuating, Hierarchy enhancing, Bangladesh, Social conflicts 


\section{Introduction}

People with high social dominance orientation believe that society should be structured in terms of inequality, with some groups at the top (i.e., possessing more power and resources) and others at the bottom (Sidanius et al., 2015). History recognizes that societies throughout history have been hierarchically organized and enforced by dominant groups. Hoffarth and Hodson (2018, p-4) have defined these groups based on race, sex, nationality, ethnicity, religion, social class, region, skin colour, caste, lineage, tribe, minimal groups, or any other group distinction that the human mind can construct. Theoretically, those in more significant social status groups have the prestige, resources and power tend to maintain hierarchical relations.

According to Social Dominance Theory (SDT), as propagated by Sidanius et al., (1994), people who are high on social dominance orientation have stronger endorse in ideologies, policies, and practices that maintain hegemony rather than those that counter it (Martin et al., 2014). A controlled social system is maintained through what social dominance theorists have termed hierarchy- enhancing mythologies, meaning 'consensus in values, attitudes, beliefs, or cultural ideologies (Jetten and Iyer, 2009). Dominance by one group upon another group creates confusion, diminishes self-actualization, reduce potentialities. Skirmishes, suppression, and psychological domination often found actively present in the same working environment where groups have a difference in opinion and level of social dominance orientation (Hoffarth and Hodson, 2018). The study conducted by Nobuhiro et al., (2019) opined that social dominance orientation negatively correlated with willingness to apologies in an intergroup context.

In Bangladesh, society has given supernatural power to men. Men always tend to dominate women (Mahboob, 2017). Empowering women in Bangladesh remains a crucial discussion on women's rights organisations (Jamal, Sayeed, and Raihan, 2016). Bangladesh was ranked 139 out of 187 countries in the human development index and 47 out of 144 countries surveyed on the Gender Inequality Index in 2017. However, women enjoy much freedom in politics than education and employment (Schwab, 2017). Women's participation in the labour force has been driven primarily by the growth of the ready-made garments industry, and the spread of micro-financing operations by NGOs (Khandakar, Khadija, and Sarmin 2018). However, despite more in numbers as a workforce in the ready-made garments industry, women have been facing tremendous suppression, sexual harassment, low wages, and much more physical and psychological pressure at the workplace (Saleem, Hajra, and Jamil, 2016)

The managerial group with greater supremacy in education, decision-making power, intellectuality, and social status tends hierarchical enhancing orientation. Managers in the manufacturing industries of Bangladesh believe that traditional distributions of power and status should be maintained within society (Kindornay, 2018). The managerial group with a high level in social dominance orientation will tend to believe that members of traditionally considered high status should be hierarchically superior to members of low-status groups (workers group). Often this belief creates conflicts and breaches industrial peace and harmony. Workers group, on the other hand, believe that society should be structured 
inequality.

There is a real scarcity of social dominance orientation literature in the Bangladesh context. SDT is still under study and yet to find generalisability in many countries (Cargile and Beach, 2017; Hoffarth and Hodson, 2018; Nobuhiro et al., 2019). Research work is necessary to find out the answer to core questions "whether or not social dominance orientation is another reason for which industrial relation in Bangladesh loses peace and harmony several times in now and then.

In this work, we examined that individual and group based social dominance orientation is responsible for social unrest in the workplace environment. The objectives of this study are to identify the degree of social dominance orientation of men and women at the workplace in Bangladeshi Textile Industries and as per the theoretical orientation of SDT, if managerial groups have a high level of social dominance orientation over the workers' group.

\section{Literature Review and Working Hypotheses}

Social dominance orientation is a new conceptualization and measurement which deals with individual differences in the preference for group-based hierarchy and inequality (Sidanius et al., 1994). Social dominance orientation is based on SDT, which was developed by Jim Sidanius and Felicia Pratto in 1994. Social dominance orientation focuses on individual and structural factors that contribute to various forms of group-based oppression (Newman, Hartman, and Taber, 2014). It is a measure of someone's support for group-based hierarchies. It is the belief someone holds toward hierarchies in general, and his group should dominate another group/s. The human being with higher-level social dominance orientation opines that society should be build or structured in inequality (Sidanius et al., 2015). They have a firm belief that some groups should remain at the top with power, resource, and social honour. There is another type of group in the society known to have low social dominance orientation and seek hierarchy-attenuating roles, in contrast, believe that society should be built with equality (Sidanius et al., 1994).

There are a variety of personality traits identified in social dominance orientation study, importantly political behavior and communication. Social dominance orientation is best known as individual difference factors having emotional, attitudinal, and behavioural orientations to intercultural relations (Romager, Hughes, and E., 2017). Social dominance orientation is based on Social Dominance Theory (SDT), which postulates that human societies tend to be organized as systems of group-based social hierarchies. SDT propagates that group inequality is disseminated through hierarchy-enhancing forces. People with a high level of social dominance orientation are motivated to maintain group-based inequality. The managerial group was enjoying the social benefit, and educational supremacy is believed to take pleasure of an unequal share of power and wealth, access to higher-quality facilities, established security, comfort, and leisure (Mari, Franc, and Šaki, 2008).

In the last few years, Bangladesh has faced political crisis, natural and human-made calamities. Inflation and fiscal insufficiency, labour unrest, protest, and blockade have all affected the economy of the country. Increased revenue earned by ready-made garments 
industry, activities of Non-Government Organization (NGO) and micro-credit facilities indicates that Bangladesh more and more Bangladeshi women have been observed in the workforce. Bangladeshi women must face many difficulties in a dominant male society (Yasmin and Islam, 2018). It is believed that men are enjoying more supremacy and social power to dominate their female counterparts. Thus, it can be hypothesized that men might be demonstrating a higher level of social dominance orientation at the workplace $\left(\mathrm{H}_{1}\right)$.

Managerial groups by their education, social status, intellectual supremacy and power in decision making may demonstrate a higher level of social dominance orientation. According to the SDT, any group that dominates over another group with their power, intellectuality, wisdom, and social status is likely to show high-level Social Dominance Orientation and high level in social inequality (Saleem, Hajra, and Jamil, 2016). In group-based dominance, the managerial group in Bangladesh is likely to seek hierarchy-enhancing. Islam (2012), in a study of workers' quality of work-life, opined that the Bangladeshi worker group enjoys little social facilities. Inadequate and unfair compensation, unsafe and unsatisfactory work environment, less access for career growth and security, social integration in the work organization are few among many reasons for which workers group often conflict with the managerial group. According to SDT, the workers' group is supposed to believe in hierarchy-attenuating orientation. They should support the concept of social equality. Thus, it can be hypothesized that the managerial group may demonstrate a high level of social dominance orientation than the workers' group $\left(\mathrm{H}_{2}\right)$.

\section{Research Method}

A quantitative research method was envisaged, where a cross-sectional study was conducted among males and females to investigate the psychosocial phenomena. The respondents belong to different seventeen Ready-Made Garments (RMG) across Dhaka and Khulna district in Bangladesh. Consent was taken from management authority before data collection and being a sensitive topic to discuss with the employee's, management's request of strict confidentiality was ensured. The research instrument included a demographic profile of the respondent (gender and employment level) and social dominance orientation scale 6 (Ho et al., 2015). The scale has 16 items with response categories of 5 on the Likert Scale, where five represents strongly agree, and one represents strongly disagree.

A total of 326 sets of instruments were distributed, but only 271 were returned. However, only 260 instruments could be used while the rest 11 were not completed correctly (more than $29 \%$ missing fields). A higher score on the social dominance orientation scale shows a higher need for dominance or posit hierarchy-enhancing ideology. Statistical Package for Social Science (SPSS) version 23.0 was used for data analysis. Descriptive statistics were recorded as frequencies. T-test was applied to calculate the association between the groups. P-value of less than 0.05 was considered as statistically significant.

\section{Data Analysis and Discussion}

Out of 260 respondents, 52.92\% (n-135) were working male, and 48.08\% (n-125) were working females. $29 \%$ of participants had work experience of $1-5$ years, $42 \%$ had 6-10 years 
of experience, $12 \%$ had 11-15 years of experience, and 17\% had an experience of 16 years and above. 50\% of samples are from the management group (30 from the top, 56 from medium and 44 lower level) working class, which shows the representation of different management levels. The female outnumbered the male in the workers' group. The number of respondents is equal in the management group and workers group (referring to table 1).

Table 1. Demographic Characteristics of the Samples

\begin{tabular}{|l|l|l|l|l|}
\hline \multicolumn{2}{|c|}{} & \multicolumn{2}{|l|}{ Employment Level } & \multirow{2}{*}{ Total } \\
\cline { 3 - 5 } \multicolumn{2}{|c|}{} & Management Group & Workers Group & \\
\hline \multirow{2}{*}{ sex } & Male & 84 & 51 & 135 \\
\cline { 2 - 5 } & Female & 46 & 79 & 125 \\
\hline \multicolumn{2}{|l|}{ Total } & 130 & 130 & 260 \\
\hline
\end{tabular}

Source: Researcher's Own Primary Data Analysis

A Cronbach Alpha $(\alpha)$ value of 0.641 could be achieved (see table 2). The result indicates that the scale used for data collection is moderately suitable and reliable. The value that can be interpreted in the context of the present study is a large population with only 16 items is to measure the Social dominance orientation level of the male-female and managerial group-workers group. A 16-item measurement item should have given a better Cronbach Alpha. The limitation of the scale is that in a cross-sectional study, a test-retest validity would have been perfect. However, $\alpha=.641$ is a moderate alpha level (Taber, 2016). Therefore, it can be assumed that the results are dependable.

Table 2. Measurement Scale Reliability

\begin{tabular}{|l|l|l|}
\hline \multicolumn{3}{|l|}{ Reliability Statistics } \\
\hline Scale & Cronbach's Alpha $(\alpha)$ & Number of Items \\
\hline Social dominance orientation Scale - 6 & .641 & 16 \\
\hline
\end{tabular}

Source: Researcher's Own Primary Data Analysis

Table 3 indicates a significant difference between male and female employees on social dominance orientation at the workplace. Findings report that there were differences in social dominance orientation between males and females.

Table 3. Reliability Analysis of Social dominance orientation between Male and Female

\begin{tabular}{|c|c|c|c|c|c|c|}
\hline \multirow[t]{2}{*}{ Scale } & \multicolumn{6}{|c|}{ Gender } \\
\hline & \multicolumn{2}{|c|}{ Male (n-135) } & \multicolumn{2}{|c|}{ Female (n-125) } & \multirow[t]{2}{*}{$\mathrm{t}(258)$} & \multirow[t]{2}{*}{$\mathrm{P}$} \\
\hline \multirow[t]{2}{*}{ SDO-6 } & Mean & SD & Mean & SD & & \\
\hline & 82.68 & 6.173 & 77.68 & 8.015 & 5.684 & $.000^{* *}$ \\
\hline
\end{tabular}

(**P-value is considered less than 0.05

Source: Researcher's Primary Data Analysis 
The mean value difference between males (82.68) and females (77.68) with a standard deviation of 6.173 and 8.015 respectively shows a clear difference of opinion or level of Social dominance orientation between males and females where $t$ is 5.684 and $p$ is less than 0.05 . The effect size is 0.69 , meaning a medium effect of the statistical analysis. The result confirms the rejection of the null hypothesis in favour of alternative hypothesis, thereby $\mathrm{H}_{1}$ (alternative) hypothesis is accepted.

Bangladesh has a male-dominated culture that is influenced by politics, social culture, and hierarchical enhancing domination. The previous study conducted by many scholars has explicitly opined males have a higher level of social dominance orientation than females. The results of this study accept the alternative hypothesis $\left(\mathrm{H}_{1}\right)$ rejecting the null hypothesis that males and females have equal social dominance orientation. The results indicate that males and females report different levels of social dominance orientation. $70.11 \%$ of males reflected a stronger tendency for social dominance orientation. The gender difference results on the Social dominance orientation of the present study reveal consistency with the literature review. Findings disclose that there is a significant difference between males and females on social dominance orientation. The males and females at workplace work in a kind of same conditions and situations but enjoy separate facilities. Females receive low wages, extreme sexual harassment and feel ignored. Male, on the other hand, always have a dominating attitude.

Table 4 indicates a significant difference between the management group and the workers' group. Findings report that there are differences in social dominance orientation between these two groups. The mean value difference between management group (78.33) and workers group (82.52) with a standard deviation 8.320 and 5.842 respectively shows a clear difference of opinion or level of Social dominance orientation between workers group and managerial group where $t$ is -4.702 and $\mathrm{p} 0.000(\mathrm{p}<0.05)$. The effect size is 0.58 , which shows a moderate effect.

Table 4. Reliability Analysis for social dominance orientation between Management Group and Workers Group

\begin{tabular}{|l|l|l|l|l|l|l|}
\hline Scale & \multicolumn{2}{|l|}{ Management Group (n-130) } & \multicolumn{2}{|l|}{ Workers Group (n-130) } & \multirow{2}{*}{ (258) } & P \\
\hline \multirow{2}{*}{ SDO-6 } & Mean & SD & Mean & SD & & \\
\cline { 2 - 7 } & 78.33 & 8.320 & 82.52 & 5.842 & -4.702 & .000 \\
\hline
\end{tabular}

$\mathrm{H}_{2}$ was conceptualized according to the SDT theory that managerial groups may demonstrate a high level of social dominance orientation than workers group. However, the result (table 4) revealed that workers group dominate over the managers' group. This study failed to reject the null hypothesis in favour of alternative hypothesis $\left(\mathrm{H}_{2}\right)$. While social dominance is a concern, the workers' group tends to dominate the managerial group with their strength, political power, labour rights, and organising capability. The Managers group enjoys more social security and intellectuality, however, are not organised in any form. Although the dominance by the workers over the managers' group is unethical and unwanted, at the end that is the reality. Therefore, this study finds that the assumptions of SDT may not be true everywhere and every society. There are factors which influences the dominance of one 
group over another like political condition, national culture, and strength of the group.

\section{Conclusion and Future Research Guidelines}

Bangladesh's business leaders may rethink women's empowerment at the workplace. Men's views on women at the workplace should be changed to keep pace together for the betterment of the business community. SDT propagate that any group that enjoys the social benefit, remain at the top with power, resource, and social honour seeks hierarchical enhancing role may need to reconsider. This study identified a reverse condition in practice. Workers group, although socially not enjoying many benefits, not in the top of power, having limited resources and social honour, yet they dominate over the managerial group.

The supportive literature on this phenomenon is very few in developing nations like Bangladesh. The recent literature is limited to this phenomenon, so this research may support future researches as a platform on social dominance orientation study in least developing and developing nations. Future studies should investigate the scale in some other industries like pharmaceutical industries, leather industries, and some industries from the service sector. In addition, the future study may consider many other variables and aspects like social status, political influence, the strength of the group and the concept of femininity and masculinity.

\section{References}

Cargile, A. C. (2017). Social Dominance Orientation: A Root of Resistance to Intercultural Dialogue ?. International Journal of Intercultural Relations, 60(2), 40-53. https://doi.org/10.1016/j.ijintrel.2017.09.003

Ho, A. K., Jim, S., Nour, K., Sheehy, S., Felicia, P., Kristin, E. H., \& Andrew, L. S. (2015). The Nature of Social Dominance Orientation: Theorizing and Measuring Preferences for Intergroup Inequality Using The New Sdo7 Scale. Journal of Personality and Social Psychology, 109(6), 1003-28. https://doi.org/10.1037/pspi0000033

Hoffarth, M. R., \& Hodson, G. (2018). Social Dominance Orientation (SDO). New York: Springer.

Islam, Mohammad Baitul. (2012). Factors Affecting Quality of Work Life : An Analysis on Employees of Private Limited Companies in Bangladesh. Global Journal Of Managemente And Business Research, 12(18), 23-31.

Jamal, U., Bari, S., \& Ubaidullah, R. (2016). Practice of Workers Participation Committee at the RMG Industries in Bangladesh: An Observation. Bangladesh Journal of Tariff and Trade, $1(5), 49-66$.

Jetten, J., \& Aarti, I. (2009). Different Meanings of the Social Dominance Orientation Concept: Predicting Political Attitudes over Time. British Journal of Social Psychology, 01(4), 1-21.

Khandakar, S. A., Huq, K., \& Sultana, S. (2018). Perception of Employees Regarding Participation in Decision Making and Problem Solving: A Study On Different Branches of Banks in Dhaka City. ABC Research Aleart, 6(1), 77-90. 
https://doi.org/10.18034/abcra.v6i1.324

Kindornay, S. (2018). Private Sector Engagement Through Development Co-Operation in Bangladesh. Dhaka.

Mahboob, Md A. (2017). The Impact of National Culture on the Organizational Culture: Multinational Companies Doing Businesses in Developing Countries. Thesis Archive, University of Gavle.

Mari, J., Renata, F., \& Vlado, Š. (2008). Dimensionality and Correlates of the Social Dominance Orientation Scale on Croatian Sample. International Congress of Psychology, 26.

Martin, D., Emma, S., Yotam, H., Tim, R., James, D., \& Philip, Z. (2014). Multiple Facets of Compassion: The Impact of Social Dominance Orientation and Economic Systems Justification. J Bus Ethics. https://doi.org/10.1007/s10551-014-2157-0

Newman, B. J., Hartman, T. K., \& Taber, C. S. (2014). Social Dominance and the Cultural Politics of Immigration. Political Psychology, 35(2), 165-86.

https://doi.org/10.1111/pops.12047

Nobuhiro, M., Kazunori, I., Shoko, K., Yohsuke, O., \& Atsushi, T. (2019). Social Dominance Orientation as an Obstacle to Intergroup Apology. PLOS ONE, 14(1), 1-8.

https://doi.org/10.1371/journal.pone.0211379

Romager, J. A., Kamran, H., \& Trimblem, J. E. (2017). Personality Traits as Predictors of Leadership Style Preferences: Investigating the Relationship Between Social Dominance Orientation and Attitide Towards Authentic Leaders. SOCIAL BEHAVIOR RESEARCH AND PRACTICE, 3(1), 1-9. https://doi.org/10.17140/SBRPOJ-3-110

Saleem, T., Bibi, H., \& Tayyaba, J. (2016). Original Article Social Dominance Orientation Across the Gender at Workplace. Journal of Islamabad Medical \& Dental College, 5(1), 33-66.

Schwab, K. (2017). The Global Gender Gap Report. Geneva.

Sidanius, J., Lisa, M., Stallworth, F. B., Felicia, P., Jim, S., Lisa, M. S., \& Bertram, F. M. (1994). Social Dominance Orientation : A Personality Variable Predicting Social and Political Attitudes Social Dominance Orientation: A Personality Variable Predicting Social and Political Attitudes. Journal of Personality and Social Psychology, 67(4), 741-63. https://doi.org/10.1037/0022-3514.67.4.741

Sidanius, J., Ho, A. K., Jennifer, S., Nour, K., Felicia, P., Kristin, E. H., Rob, F., \& Andrew, S. (2015). The Nature of Social Dominance Orientation: Theorizing and Measuring Preferences for Intergroup Inequality Using the New SDO7 Scale Group-Based (in Press). Journal of Personality and Social Psychology.

Taber, K. S. (2016). The Use of Cronbach's Alpha When Developing and Reporting Research Instruments in Science Education. Cross Mark Scientific Education, 24(1).

Yasmin, N., \& Enamul, I. (2018). Revitalization of Nakshi Kantha through Modern Stitching 
Technology. Elixir International Journal, 120(2), 51366-69.

\section{Copyright Disclaimer}

Copyright for this article is retained by the author(s), with first publication rights granted to the journal.

This is an open-access article distributed under the terms and conditions of the Creative Commons Attribution license (http://creativecommons.org/licenses/by/3.0/). 